\title{
iC亘TL
}

International Conference on Research in Education, Teaching and Learning

Paris, France| November 2 -4, 2018

\section{Research Training For the Knowledge Society: Experience in the «Step into the Future» Program}

\author{
A.O. Karpov \\ Bauman Moscow State Technical University
}

\begin{abstract}
Evolving capacities of schoolchildren for active cognitive activity is one of the main factors in establishing the knowledge society. This paper presents key findings of theoretical study of the problem of research education for schoolchildren who show special aptitudes and high outcomes in scientific and engineering activities. The basis of the developed theory is 25 -year experience in implementation of the Russian «Step into the Future» program, where more than 150 thousand talented youngsters take part every year. A brief description of the scientific and educational activities under the «Step into the future» program is presented in the context of research training for schoolchildren in the Western world. The following key concepts of the developed theory are discussed: scientific-type research behavior, generative environment and learning method, problem-cognitive program, network institutionalization and stages of research training, school of cognitive roles and socio-cultural experience, cognitivecultural polymorphism of the educational system. Examples of scientific research training for schoolchildren that illustrate interrelations between the developed concepts are presented.
\end{abstract}

Keywords: Education, Research, Science, Cognition, School, Theory 
